\title{
ALISA OVDE I SADA: SAVREMENA KNJIŽEVNOST U UNIVERZITETSKOJ NASTAVI
}

APSTRAKT: Ulazak savremene književnosti u univerzitetsku nastavu nije uvek metodološki jednostavan, iako bi se moglo učiniti da se korišćenjem aktuelnijih narativa koji su, direktno ili ne, odjek recentnih istorijskih i kulturnih okolnosti, postiže adekvatnija korelacija kako sa ostalim nastavnim sadržajima tako i sa ličnim i generacijskim prioritetima studenata. Nedostaje kritička recepcija i književnoteorijska evaluacija koja bi predavaču pomogla da vrednuje književno delo ali, s druge strane, podsticajno je usmeriti studente da sami potraže interpretacijski ključ u ličnom iskustvu i generacijskim opredeljenjima. Analiza romana Uhvati zeca Lane Bastašić ukazuje na mogućnosti uvođenja savremene književnosti u kurikulum.

Ključne reči: savremena književnost, nastava, rod, kanon, kurikulum.

\section{ALICE, HERE AND NOW: CONTEMPORARY LITERATURE IN UNIVERSITY TEACHING}

ABSTRACT: Introducing contemporary literature into university teaching is a challenge in terms of the methodological approach, although it seems that employing current narratives which might, in one way or the other, resonate with readers as historically or culturally referential, correlates with both some other teaching contents as well as students' personal and generational priorities. Contemporary literary texts lack critical reception and theoretical evaluation which might help the teacher determine their relevance, but, on the other hand, encouraging students to search for an interpretational key within their personal experience and generational choices is worth the effort. The analysis of the novel Catch the Rabbit by Lana Bastašić indicates the potential of introducing a work of contemporary literature into the curriculum.

Key words: contemporary literature, teaching, gender, canon, curriculum.

\section{UVOD: KANON I KURIKULUM}

Definicije književnog kanona menjaju se sa svakim novim metodološkim pristupom: tradicionalisti, poput američkog teoretičara Harolda Bluma, smatraju da je kanon nasušna potreba i da bez njega „prestajemo da mislimo” (Bloom 1994: 41). Međutim, ovakvi načelni iskazi ne govore nam mnogo dok ne počnemo da uviđamo šta se krije u njihovom podtekstu: Blum se protivi inicijativi da se estetski 
standardi u proceni književnosti zamene etnocentričnim i rodnim kriterijumima, smatrajući da se društveni ciljevi ne mogu postizati takvim razgraničenjima, bar ne u književnosti. Ovaj teoretičar jasno i nedvosmisleno insistira na izuzetnosti u njenom klasičnom značenju. Bori se za radost čitanja, reaktualizuje (po mnogima anahron) metod kritičkog impresionizma i zagovara konzervativne vrednosti. „Književnog genija, a njega je teško definisati, ne možemo otkriti bez usredsređenog čitanja”, piše Blum (Bloom 2002: 3). „Čitalac uči da se identifikuje sa onim što oseća kao veličinu koja može da upotpuni jednu ličnost, a da ne ugrozi njen integritet. 'Veličina' je možda izašla iz mode, kao i transcendentalno, ali je teško živeti bez nade da ćemo naići na izuzetnost." (Bloom 2002: 3-4).

Blumov metod vrednovanja zasniva se na poređenju, jukstaponiranju i sintetičnosti, a kao protivnik novije francuske filozofije i ideje Rolana Barta o suštinskoj nepročitljivosti (illisibilité) književnog dela (Richaudeau 1970: 19), bori se da prevagu nad remek-delima ne odnesu njihove parodije i da se u procesu profilisanja novih klasika odbaci kriterijum političke korektnosti i obaveza kulturne raznovrsnosti. Ovaj teoretičar želeo je da čitanju prida punu spiritualnost i tako što je svojih sto genija svrstao u deset grupa, od kojih je svaka nosilac jednog od deset kabalističkih božanskih atributa.

Činjenica je, ipak, da u nauci o književnosti danas preovlađuje argumentacija one struje teoretičara koja smatra da bi kanon morao da bude inkluzivan i kulturno reprezentativan, te da je njegov zadatak da inkorporira različitost identiteta i kulturni diversitet, tim više zbog toga što „konzervativni edukatori pružaju otpor svakom potezu koji bi umanjio autoritet kanona" (Pike 2002: 355). U pokušaju da bude pomirljiv, književni teoretičar i istoričar Teri Iglton izvodi jednu, na prvi pogled vrlo neodređenu definiciju, koja otkriva suštinu: kako on kaže, kanon stvaraju „,naročiti ljudi iz naročitih razloga u izvesnom vremenskom trenutku" (Eagleton 1983: 11), ukazujući tako na ono svojstvo kanona koje bi trebalo da se podrazumeva, a koje i tradicionalni i moderni teoretičari gube iz vida - književni kanon je, naime, specifičan proizvod određenih istorijskih i kulturnih okolnosti.

Kako kažu Barnet i Kout, zamisli o obrazovanju dejstvuju samo kroz kurikulum (Barnett \& Coate 2004: 25), a u okviru njega uspostavljaju se vrednosti, načela i principi povezani s učenjem, razumevanjem, znanjem i pojedinačnim disciplinama. Reklo bi se, međutim, da u posredovanju kanonskih vrednosti kroz kurikulum najmanje uticaja imaju oni koji po njemu uče. Helen Dej je pokušala da rezimira stavove svojih studenata o prioritetima, vrednostima i stavovima koje usvajaju tokom procesa obrazovanja, došavši do zaključka da ,predavači predaju u skladu sa svojim disciplinama, a (ponekad i) usko definisanim predmetnim 
poljima” (Day 2007: 536); jedna od teškoća koju ona naročito ističe jeste to što studenti nisu podsticani da formiraju holistički pogled na materiju koja je predmet učenja - manjka im perspektiva „helikoptera”, kako Helen Dej to duhovito a precizno naziva. Uz pomoć ove neobične metafore dolazimo do suštine, do dimenzije u kojoj uloga književnog kanona treba da bude najvažnija: ma kakav odnos prema kanonu imali, bilo da ga smatramo neprikosnovenim, bilo da ga proglašavamo patrijarhalnim, zastarelim ili, uopšte uzev, zrelim za redefinisanje i promene, on mora da demonstrira tu važnu funkciju posredovanja holističkog, integrativnog pogleda na književnost.

Poriv da se književno nasleđe preusmeri i izmeni danas mahom podrazumeva želju da se nevidljivi elementi kulture učine vidljivim, prisutnim i relevantnim, što se postiže tako što se marginalizovani i zanemareni autori uvrštavaju u referentnu literaturu i kurikulum. Međutim, uvođenje recentnih književnih tekstova ne znači nužno da je njihovo čitanje u učionici jednostavnije od čitanja tradicionalnih, kanonskih tekstova, niti da će učenici i studenti biti dodatno motivisani da ih analiziraju: problemi čitanja, razumevanja i tumačenja nisu ni umanjeni ni eliminisani kad pažnju usmerimo na književna dela novijeg datuma, a razlog tome leži u činjenici da svako tumačenje zahteva metodologiju i definisan teorijski pristup, bez obzira na to kojoj istorijskoj i stilskoj epohi pripada tekst. Zabluda je da se teškoće u razumevanju automatski smanjuju smanjivanjem istorijske distance koja razdvaja trenutak pisanja i trenutak čitanja - plodotvorna interpretacija počinje tamo gde se jasno i nedvosmisleno uvedu teorijski postulati koji će poslužiti kao temelj pristupa književnom tekstu.

Promene u kurikulumu predočavaju prethodne promene u načinu na koji definišemo kulturu: ne treba, naime, smetnuti s uma da je od definicije Metjua Arnolda, po kojoj je kultura, da parafraziramo, ono što je najbolje među plodovima ljudskog mišljenja i pisanja, pojam doživeo mnogo modifikacija, da bi se dospelo do određenja koje iznosi teoretičar Rejmond Vilijams, u kome on kulturu definiše kao „celokupan način života” (Williams 1960: 254).

Studije kulture podrazumevaju tri aspekta: zaokupljenost zbirom raznorodnih tekstova koji nisu samo književni, multidisciplinarni pristup koji proishodi i iz društvenih nauka i iz humanistike, kao i naglasak na teoriji s obeležjima autorefleksivnosti (Frith 1992: 4). Stoga, ukoliko čitanje savremenog književnog teksta bude praćeno jasno definisanim pristupom koji uključuje prepoznavanje i razumevanje istorijskih, društvenih i kulturoloških činjenica koje kontekstualizuju književni tekst u vremenu i prostoru, time je veća verovatnoća da će susret sa književnim delom studentima biti zanimljiviji. 


\section{PRED VRATIMA KANONA}

Premda u knjizi Genije ima ambiciju da konstruiše mozaik koji će obuhvatiti sto najvećih kreativnih umova svetske književnosti i kulture, a takođe i da kreira neku vrstu periodičkog sistema književne istorije, Harold Blum se ne odriče iznošenja ličnih stavova i naglašavanja ličnih afiniteta $u$ vrednovanju beletristike, te se tako ne usteže ni da izrazi divljenje Luisu Kerolu i njegovim romanima o Alisi: „Onda kada je dečja književnost zaista postojala, njena remekdela bila su ona Kerolova." (Bloom 2002: 742). Blum će kategorički tvrditi da je „loše pisanje loše po decu” i da će knjige o Hariju Poteru, „dela pretrpana klišeima”, završiti u „kantama za smeće” (Bloom 2002: 742). Ne treba, ipak, misliti da su ovakve, vrlo zaoštrene, izjave motivisane samo omalovažavanjem jedne uspešne franšize kakva je serija romana Dž. K. Rouling. U sedmoknjižju o dečaku čarobnjaku ima mnogo elemenata koji idu u prilog savremenim vrednovanjima književnog dela: autorka romana o Hariju Poteru gradi fiktivni svet na sličnim principima na kojima se zasnivaju zamišljeni svetovi realističkog romana - na principima socijalne hijerarhije i fluktuacije moći kojima se dodaju elementi potrage, sukoba dobra i zla, kao i iskušenje građenja i primene etičkih merila u svakodnevnom životu. Arhetipski elementi su osavremenjeni, tako da Voldemor, na primer, od dijaboličnog junaka u stilu Miltonovog Satane do kraja sedmoknjižja izrasta $u$ autentičnu terorističku pretnju, pretnju koja je internalizovana u samom sistemu i ima moć da ,probudi” pasivizirane sledbenike Onoga-koji-se-ne-sme-imenovati. Svako delo o Hariju Poteru je u jednakoj meri roman traganja i roman odrastanja, budući da je glavni junak iskusio socijalne i kulturne konflikte, egzistencijalnu pretnju i smrtnu opasnost, kao i s obzirom na to da je pratio kako nastaje globalna zavera zla protiv dobra; Hari doživljava nepravde, potcenjivanje, mržnju, izolaciju, konflikte sa korumpiranim i vlastoljubivim pojedincima i sistemom, postaje, u nekim trenucima, žrtva medijskog rata, političkih igara i imperativa društvene hijerarhije, mučen tajnama rodnih, identitetskih, genealoških razlika i traumiran gubitkom očinske figure. Svi se ovi formalni (žanrovski), tematski i idejni aspekti prepoznaju u procesima čitanja, tumačenja, analize teksta i primene različitog spektra teorijskih metoda.

Hari Poter objedinjuje vrline i mane mnogih junaka koji su se u istoriji književnosti etablirali kao arhetipski, od Odiseja pa sve do Jozefa K. iz Kafkinog Procesa, a sve njegove patnje $\mathrm{i}$ iskušenja su refleksija prepreka s kojima se arhetipski lik suočava. Međutim, uvid u uticaje koji su obrazovali književnog junaka ne ukida potrebu da se istraži da li je Hari Poter ipak nešto više od individualnog junaka, više od paradigme heroja dečje književnosti. 
Kontekst u kome deluje Alisa ne čini se tako obuhvatnim kao onaj koji Dž. K. Rouling stvara. Ipak, Kerolova junakinja slovi za jedan od najintrigantnijih likova u anglofonoj dečjoj književnosti. Iz Alise u zemlji čuda detalji socijalne hijerarhije i kulturnih obeležja prividno su izostavljeni, ali se ostvaruju u drugačijoj dimenziji fantastičnog, u kojoj elemente društvene kritike, satire, parodije i ideološkog angažmana zamenjuje i, možemo reći, natkriljuje konvencija snoviđenja, odnosno oniričkog predstavljanja realnosti. Roman o Alisi, devojčici koja putuje kroz svet apsurda koji se opire svakom njenom racionalnom pokušaju interpretacije, nije samo klasik dečje književnosti, nego i zavodljiv eksperiment na temu teorije haosa. Zaplet Alise u zemlji čuda može se opisati dvojako: kao avantura identiteta i kao avantura znanja; tome u prilog govori i česta tendencija da se roman posmatra kao komični mit o problemu smisla i o potrazi za njim u svetu koji se posmatraču čini kao nasumičan i potpuno obesmišljen. Remek-delo Luisa Kerola na originalan način pristupa izazovu otkrivanja i sagledavanja ontoloških principa na kojima počiva realnost, a to je esencijalno pitanje kojim se bavi celokupna fantastična književnost: ona se pita kakav je svet u stvari, da li ga, i kako, možemo spoznati, kakvo to mesto čovek u njemu zapravo zauzima. Iza Kerolove stvaralačke mašte i jezičke invencije skriva se čitava jedna nova dimenzija - dimenzija filozofske meditacije o pojmovima stvarnog i nepostojećeg, sna i realnosti, prolaznosti i večnosti, logike i apsurda, pravila i anarhije.

Ako karakterizaciji glavne junakinje pristupimo iz kulturološkog i rodnog aspekta, Alisa se ukazuje kao izvrnuta paralela viktorijanske žene čija je radoznalost nagrađena avanturom (makar se ta avantura odigrala samo u snu): ta se avantura suprotstavlja logici i sistemu po kojima funkcioniše građanski svet, a to je svet u kome je ženi poveren samo prostor oko domaćeg ognjišta, i u kom je ona lišena svake inicijative; sve što je izvan granice doma predstavljeno je kao pretnja, opasnost i prostor seksualnog sagrešenja, moralnog posrnuća ili čak zločina. Kao književna junakinja, Alisa je samo delimično modelovana prema principima koji poriču autonomnost ženskog bića: raste i smanjuje se, zaboravlja jezik i ponovo ga uči, ali autor sve vreme insistira na pasivnosti junakinje i na njenom krotkom, pomirljivom prihvatanju zadatih stanja, ma koliko se promene koje joj se dešavaju protivile principima zdravog razuma.

Uhvati zeca, roman Lane Bastašić (1986), spisateljice rođene u Zagrebu, koja je odrastala i školovala se u Banjaluci, a potom se nastanila u Barseloni, gde danas vodi školu kreativnog pisanja, specifičan je ne samo po nizu tema koje razmatra, ne samo po stilu i postupku, nego i po recepcijskim odjecima koje pokreće. Inspirisan je Alisom $u$ zemlji čuda i korpusom dečje književnosti, zasnovan na konvencijama književne fantastike, ali se bavi vrlo delikatnim temama 
odrastanja i sazrevanja u posleratnom, postjugoslovenskom okruženju. Roman se plasirao u najuži izbor za NIN-ovu nagradu kritike za roman godine i izazvao priličnu čitalačku i kritičarsku pažnju u Srbiji i zemljama regiona. Ono što ga čini izuzetnim jeste i bavljenje ženskim prijateljstvom, inače marginalizovanim i potcenjenim motivom u srpskom književnom stvaralaštvu: ravnopravne junakinje su Sara i Lejla, prijateljice iz detinjstva koje se ponovo sreću nakon dvanaest godina kako bi krenule na zajedničko putovanje potrage i sazrevanja, na putovanje koje će im možda donekle razjasniti njihov složen i slojevit odnos.

Roman mlade ali već afirmisane autorke koja se okušala u pisanju poezije i proze može da posluži za književnu analizu u okvirima univerzitetske nastave kako zbog svog kvaliteta tako i zbog aktuelnosti tema kojima se bavi: odrastanje, rat kao deo iskustva, formiranje predstava o nacionalnom, rodnom i kulturnom identitetu, samo su neke od njih. Književni kritičari koji su do sada pisali o knjizi Uhvati zeca isticali su tematske i motivske srodnosti sa nizom ostvarenja klasične i savremene književnosti, od Luisa Kerola do Elene Ferante, ali su ukazivali i na njegove vrhunske domete: „Uhvati zeca je odličan roman. Reč je o knjizi koja seže u nemali broj potisnutih i marginalizovanih mesta istorijskog, poetičkog i rodnog iskustva postjugoslovenskog prostora." (Svirčev 2019: 184). Kao izuzetno važna određenja, književna kritičarka Žarka Svirčev navodi i ona žanrovska - roman svrstava u „Bildungsroman i road fiction“ - koja omogućavaju da se narativni postupci odrastanja i sazrevanja, uz teme traume i suočavanja s prošlošću, uobliče u koherentnu celinu.

\section{IZAZOVI I ZAMKE INTERPRETACIJE POSTJUGOSLOVENSKE PROZE}

Putovanje prostorom nekadašnje Jugoslavije koje se pretvara u potragu za sećanjem, istorijom i identitetom: tako bi se mogao opisati drugi roman Lane Bastašić - prvi, Trajni pigmenti, objavljen 2010, takođe inkorporira autobiografski materijal na teme odrastanja u okruženju rata i egzistencijalne nesigurnosti - koji jeste fantastički parabolični sunovrat u prošlost, u detinjstvo, u oblikovanje emocija, duha i duše, u bezuspešan pokušaj mirenja sa poreklom kao zadatim identitetom. Na kraju romana očituje se da je potraga za korenima osuđena na neuspeh ukoliko u poreklu tražimo odgovor na sva pitanja koja nas muče: cikličnom formom naracije u kojoj se sve potrage vraćaju na početnu tačku sugeriše se da se koreni ne otkrivaju nakon dugog traganja zato da bi se slavili i idealizovali, već da bi se od njih što dalje pobeglo. Poreklo Sarinog i Lejlinog identiteta sakriveno je, potisnuto, a možda čak i nepovratno izgubljeno u istoriji ratova, mržnje i konflikata sa kojima su nesposobne da se suoče. Ponovni susret 
dveju prijateljica nije nostalgičan, romantičan niti obećava mirenje i idilu, naprotiv: taj susret je silazak u mračne hodnike prošlosti, o čemu svedoče reči Sare, koja je istovremeno i dramatizovana naratorka, sa čijim viđenjem nepouzdanog pripovedača čitalaštvo sve vreme mora da se nosi, interaktivno preispitujući njene motive i porive. „Lejlin poziv mi je napravio muzej od života” (Bastašić 2018: 25), kaže Sara, znajući da predstojeće putovanje sa Lejlom nije „dvonedjeljni odmor”, već je „kao da se vratiš heroinu” (Bastašić 2018: 25). Ovako postulirati osnovnu ideju romana znači duboko se posvetiti najvažnijim pojmovima jedne kulture: načinu života i načinu mišljenja koji predodređuje sudbinu pojedinaca u zaoštrenim životnim okolnostima.

Kako navodi Žarka Svirčev, u romanu su ,formiranje identiteta i sazrevanje, kao i dinamika međusobnog odnosa” predočeni ne samo individualnim obeležjima, već i ,specifičnim pozicijama obeju devojčica, odnosno žena, na čemu se posebno insistira - njihovim rodom, odnosno patrijarhalnim kontekstom koji ga nastoji oblikovati, klasnim statusom, nacionalnom i verskom pripadnošću" (Svirčev 2019: 185).

Na mnogo načina, roman Uhvati zeca korespondira sa životom generacija odraslih u postjugoslovenskom miljeu: glavna junakinja Sara rođena je i odrasla u Banjaluci, ali je nakon završenih studija otišla u Irsku i tamo nastavila život i obrazovanje. Formativne, osetljive godine njenog puberteta i adolescencije tekle su početkom devedesetih, a Sarin razvoj paralelan je, a istovremeno kulturološki i iskustveno suprotstavljen, odrastanju njene najbolje prijateljice Lejle, koja je zbog svoje pripadnosti muslimanskoj verskoj zajednici prinuđena da promeni ime i prilagodi se većinskom stanovništvu, ali ne i dominantnom mentalitetu: čak i sa neznatno drugačijim imenom, ona je jednako nekonvencionalna. Razdvojene vremenom i u odrastanju ustanovljenim razlikama, Sara i Lejla se ponovo sreću, ovaj put u Mostaru, gde Sara dolazi nakon Lejlinog poziva da otputuju u Beč i sastanu se tamo s njenim bratom Arminom.

Parabola i paradoks združeni su u nedeljivu simbiozu stoga što je Sarin polazak na put sa Lejlom istovremeno i čin potpunog poverenja i let sa slepom navigacijom, baš kao i Alisin pad kroz zečju rupu. Pokorno sledeći poziv koji je iz temelja promenio njen odnos prema sadašnjosti, a na koji je faktički čekala dvanaest godina, Sara se vraća u svet detinjstva, u jezik, u prapočetak osećanja ljubavi, odnosno u prvu fasciniranost jednim muškarcem i jednom ženom, Arminom i Lejlom. To dvoje Begića, u pokušaju da neutrališu nacionalnu napetost u Banjaluci devedesetih gde nečija zla ruka iz mraka truje pse, postaju Marko i Lela Berić, i njihova, u svođenju na jedno slovo prezimena naoko jedva primetna, promena identiteta prva je Sarina životna lekcija o hegemonijskom diskursu, o 
normativima koji u socijalnom okruženju iznenada počinju da važe čim se zaoštri politička situacija.

Sara uporno opisuje i pripoveda, ne verujući ni sama da pripovedanjem i opisima stižemo do spoznaje dubljih značenja. Njena najbolja prijateljica Lejla će ostati neuspešno predočena misterija jer se i sama opire svrstavanjima, zato što svim onim što čini i govori zapravo unosi zbunjenost i nered u svaki pokušaj definisanja. Sara Lejlu vidi kao znamenje pobune, lične i generacijske, jedino što se ta pobuna manifestuje više kao mirno iskazivanje nehaja za običaje i zakone nego kao organizovana strategija otpora. Lejla želi da bude sveprisutna, da bude u centru Sarine pažnje, ali da istovremeno onemogući svaki njen pokušaj pripovedanja: „Kad bi mogla, zavukla bi mi se između dvije rečenice kao moljac među dva rebra na venecijaneru", kaže Sara za Lejlu (Bastašić 2018: 7), jer Sarin život je upravo pokušaj da se reši misterija najbolje i najbliže prijateljice, da se ponovi fascinacija njihovim prvim zajedničkim iskustvima, ali istovremeno i pokušaj da se Sara oslobodi onog što naziva Lejlinim „suptilnim nasiljem” (Bastašić 2018: 8), i da zaobiđe rodnu Bosnu „kao grofica kakvog prosjaka na putu ka operi” (Bastašić 2018: 8). Opis moljca zavučenog između dva rebra venecijanera izabran je da bi predočio suženost, ograničenost pogleda $\mathrm{i}$ iskustvo koje je nemoguće ukloniti iz vidokruga, ali ga je isto tako nemoguće i razrešiti.

\section{PUTOVANJE I ODRASTANJE KAO DOMINANTNI MOTIVI: IDENTITET I NJEGOVE ZAGONETKE}

Koliko su prva iskustva važna glavnoj junakinji, pokazuje i činjenica da su sva njena životna opredeljivanja neka vrsta ponavljanja i varijacije ranih uspomena. To vidimo i na osnovu opisa kako je započela Sarina irska romansa, ljubav s Majklom i zajednički život s njim. I ljubavno iskustvo ranog zrelog doba jedne žene gradi se na ehu prošlosti i na analogijama sa prvim iskustvima: nakon prvog intimnog kontakta, koji je nije učinio naročito srećnom ni zadovoljnom, Saru će Majklu silovito privući otkriće da među njegovim knjigama postoji i roman Roberta Luisa Stivensona Ostrvo s blagom. To je detalj koji će je navesti da se vrati u njegov krevet i prespava do jutra umesto da se tiho išunja iz stana. Više decenija omiljena lektira dece u školskom uzrastu koja je doživela preko četrdeset izdanja u vreme SFR Jugoslavije, Stivensonov roman je i omiljena knjiga Lejlinog brata Armina, a to je razlog što ga je Sara i sama bezbroj puta čitala. Sa druge strane, pitanja o omiljenim stvarima kojima je Armin zasipa na proslavi Lejlinog sedmog rođendana Saru će uvesti u praksu komunikacijskog rituala koji se zasniva 
na anketiranju sagovornika o omiljenim stvarima; takva će vrsta radoznale istrage označiti i začetak njene ljubavi s Majklom.

Put u Beč na koji dve drugarice kreću nije put potrage, kao što Sara misli, već put sećanja, kao što Lejla od samog početka vrlo dobro zna. One idu baš u grad gde je Armin u muzeju Albertina kao sedmogodišnji dečak „dirnuo Direra” (Bastašić 2018: 19; isti se izraz u identičnoj rečenici ponavlja i na stranici 260), i to dodirivanje slike koja se nikako ne sme dotaknuti svedoči da je iskorak iz sistema pravila i zabrana uvek onoliko moguć koliko je opasan i zabranjen. Jedna od dilema koje roman pokreće, a važna je i za analizu u učionici, jeste motivacija dveju devojaka, koja se svodi na Armina, na odsutnog muškarca koji definiše njihov odnos ovde i sad. Žarka Svirčev navodi da roman Uhvati zeca ipak govori o ženskom identitetu ,jer je, i pored izrazitih razlika i specifičnosti obe junakinje, njihov zajednički imenitelj diskurzivno oblikovanje patrijarhalnim patronatima (ponajviše odsutnim bratom) (podvukla VGP) čiji se represivni učinci ogoljavaju." (Svirčev 2019: 185).

Dve prijateljice je moguće sagledati ne samo kao dve mlade žene koje proživljavaju blaženstva i traume, nego i kao simboličke funkcije ljudskog uma. Lejla je imaginacija, mašta i tekst koji se otimaju tvorcu, Sara je bezuspešni analitički racio, opsesivna, kako je Lejla u više navrata opisuje. Njih dve možemo posmatrati i kao proizvod vaspitanja njihovih roditelja: Lejlini roditelji su otvoreniji i tolerantniji, Sarini insistiraju na rigidnosti i disciplini, nespretni su i neartikulisani kada pokušaju da pokažu emocije. Lejlin otac, koji je umro od tumora u grlu dok je ona bila mala, bio je pevač sevdalinki; Sarin otac, koji će umreti kad je ona već uveliko nastanjena u drugoj zemlji, radi kao načelnik policije. Očevi su osmišljeni kao suprotstavljeni koncepti koji dodatno zaoštravaju identitetske razlike dve devojke: jedan je orfička figura umetnika, drugi otelovljuje vlast i red, monotoni automatizam autoriteta i kontrole, nalog discipline i lišavanja. Kako Sara doživljava oca vidimo i po tome što ona $\mathrm{u}$ njegovom prisustvu sistematski izbegava da jede slatkiše i šećer, da ne bi postala gojazna i malodušna kao što je njena majka. Sarin otac je u izvesnoj meri i dijabolični lik, jer nosi štap i ima „lijenu nogu” (Bastašić 2018: 70) koja ga sprečava da se ,riješi gamadi”: o kakvoj se gamadi radi, otkriva govor pun uvredljivih kvalifikacija i nultog stepena tolerancije za sve što je drugačije kojim se otac obilato služi. On leži na kauču lenjo i opušteno, pije zeleni čaj zato što je dobar za metabolizam, njegova briga za sebe povezana je sa potpunim nehajem za sve druge, a naročito za one drugačije. Kada se Lejlinom bratu Arminu izgubi svaki trag, Sarinog oca taj nestanak ne uznemirava, jer mladića opisuje kao „malog debila”, a kad Arminova i Lejlina majka dođe u policiju da se raspita za nestalog sina, bezdušno joj kaže da su „svi ti 
dripci što su nestali, i Habdić, i mali Šehić (...) prvi osumnjičeni za zločin nad našim psima i da je bilo pitanje vremena kad će neko da popizdi." (Bastašić 2018: 69). Povezivanje nestanka ljudi sa ubijanjem pasa jasna je indikacija međunacionalnog konflikta, budući da je očigledno da su svi oni koji su netragom nestali iste etničke pripadnosti, i da se svim slučajevima nestanka posvećuje jednako malo pažnje.

Sarin otac je svoju kćer odveo da se krsti u pravoslavnoj crkvi na njen trinaesti rođendan, što jasno ukazuje na njegovu potrebu za socijalnom integracijom i za prestrojavanjem na ideološki kolosek koji smatra ako ne ispravnim, ono bar aktuelnim. U želji da poštuje sva pravila, Sari otac daruje i zlatni medaljon na lancu kao maturski poklon: u pitanju je neželjen i nepodesan dar koji ukazuje kako između oca i kćeri nema bliskosti ni razumevanja, niti saglasja o tome šta jeste zrelost, i kako se ona obeležava i doživljava. Taj će glomazni komad nakita u Irskoj biti pretvoren u novac za egzistencijalne potrebe. Život u egzilu zahteva da, zarad pukog preživljavanja, junakinja u zalagaonici ostavi svoje uspomene, pa će tamo završiti i zlatni lanac dobijen od oca, i prstenje koje je pripadalo njenoj baki. U pitanju je stalan motiv izgnaništva koji nalazimo i u drugim delima srpske i hrvatske književnosti, recimo kod Nine Živančević u Vizantijskim pričama i u autofikcijskom romanu Umiranje u Torontu hrvatske autorke Daše Drndić. Uglavnom je motiv prodaje porodičnih dragocenosti i uspomena signal o dodatnom nivou otuđenja, o prevrednovanju vrednosti usled egzistencijalnih imperativa.

Dolazak u Beč na kraju romana ne daje jasne odgovore, niti nudi rasplet. Na simboličkom nivou tumačenja, ukazuje se da je uređen svet u kome vladaju pravila zapravo samo nova dimenzija dekandencije od koje su devojke želele da pobegnu. Dolazak u Beč ne označava spasenje, već je početak novog košmara u kom se mora naći odgovor na pitanje kako da se živi sa kulturnim i istorijskim nasleđem svoje zemlje i svog vremena. Beč je nova enigma, koju tek treba rešiti i od koje tek treba pobeći. Sara je jasno i beskompromisno pobegla od Bosne, od usuda korena i porekla koji zadaju identitet, ali odlučno odbija i identitet koji nudi bečka dekadencija: ona želi da „uhvati zeca”, kako i sam naslov romana kaže, ali joj je potpuno jasno da je zec (bio on označitelj identiteta, saznanja, unutrašnjeg mira ili nečeg sasvim drugog) neuhvatljiv i nedostižan, da se on ne može posedovati i pripitomiti, izuzev ako se potraga za njim smesti u umetničko delo. 


\section{SLIKE KRVI I DOMA}

Simboli, rituali i metafore vezani za krv su nedvosmisleno univerzalni: ova je telesna supstanca povezana sa čitavom paletom različitih značenja, ne samo zbog specifične boje koja se, po zakonima neurofiziologije, opaža kao primarna boja spektra, nego i zbog povezanosti sa životnim ciklusima (Gordić Petković 2016: 301 i dalje).

Književnost povezuje krv sa zločinom i strašću, ali još jedan aspekt prisustva krvi kao znaka i simbola jeste krivica - krv se vezuje za krivicu, imaginarnu ili stvarnu, koja prati zločine i nepočinstva. Krv na rukama junakinja književnog dela, uvek marginalizovanih i obespravljenih u svetu patrijarhata, imaće posebno značenje, već i stoga što specifičnost ženskog položaja uslovljava čitav niz ambivalentnih reakcija, emotivnih i etičkih, na pitanja krivice, odgovornosti, (samo)kažnjavanja i ispaštanja (Gordić Petković 2016: 301 i dalje).

Krv u romanu Uhvati zeca predstavlja mnogo složeniji simbol i nadilazi očekivana značenja i tumačenja, najvećim delom i zato što se u ovom delu telo predstavlja kao mladim ženama poznata i bliska teritorija: za Lejlu i Saru ni telo ni telesne tečnosti nisu bauk, stigma ili izvor osećanja inferiornosti - telo je ugodna zagonetka, misterija koja se rešava, tajna sa kojom se živi.

„Znala sam je duže nego što sam imala menstruaciju” (Bastašić 2018: 18), kaže Sara kad želi da otkrije kolliko već traje njeno poznanstvo s Lejlom, i to je znakovita odrednica kojom počinje koloplet slika krvi, od fizioloških (tamponi koje Lejla gotovo automatski stavlja i vadi dok se vozi na suvozačkom sedištu od Mostara ka Jajcu, bez ikakvog nastojanja da to čini diskretno ili kriomice), do identitetskih: Lejla menstruaciju dobija sa jedanaest godina, iste godine kad menja i ime. „Dobila si menstruaciju i novo ime, a ja, iako osam mjeseci starija, ništa” (Bastašić 2018: 47), sa tugom i gorčinom govori Sara u imaginarnom monologu upućenom prijateljici. „Do juče si bila Lejla, bez krvi i čista, kao i ja. Sada se u naše prijateljstvo uvukla ta prokleta Lela, koja ima menstruaciju i namjerno ne želi da mi je objasni." (Bastašić 2018: 48).

Bosna je za Saru povratak u nesvesno, nekakav otrov bez kog se ne može. Kad kaže svom partneru Majklu da će otputovati kući, oseća da je upotrebila pogrešnu reč: „Home je bio naš stan, naše knjige (...) Home nije Bosna. Bosna je nešto drugo. Zarđalo sidro u nekom popišanom moru. Bodeš se tetanusom uredno, iako su prošle tolike godine." (Bastašić 2018: 27). Zavičaj je za Saru upravo zavisnost od zagađenja, od toksičnih, štetnih materija koje su postale metafore njenog iskaza o Bosni. Dolazak u Mostar je i ponovni ulazak u jezik, ali je i taj ulazak vezan za toksične materije: „Okružile su me riječi od kojih sam se bila 
očistila, kao čovjek koji se jedva nekako odvikao od cigareta, a potom se našao zatvoren u prostoriji za pušače." (Bastašić 2018: 57). Dok se u jeziku očituje zagađenje i opasnost od trovanja, teritorija i rodno mesto su u Sarinom narativu predstavljene kao bolest: kad ih putovanje dovede do Banjaluke, ona je „hladna raka nasred naše putanje” i „vješto skrivan čir” (Bastašić 2018: 112). Međutim, kad Lejla pita „Možemo li stati kod kuće?”, to menja Sarinu percepciju; slika groblja i hladnoće koja joj se ukazala odjednom nestane: „Izvukla je Banjaluku iz zemlje u dvije riječi." (Bastašić 2018: 112).

Figure majke su crne i tužne, ili zastrašujuće: kada upozna Sarinu majku prilikom njene prve i jedine posete ćerki u Dablinu, Majkl lakonski i taktično kaže da ima lepe oči, ali Sara zna šta je on mislio: ,gledao je u njeno ogromno tijelo i pitao se da li je to u genima" (Bastašić 2018: 21). Sara ume da protumači i očev pogled upućen majci nakon što ona stavi u usta kockicu šećera umočenu u kafu; taj pogled interpretira kao da se njime kaže ,trebalo bi da pazi na kilažu, raširila se kao svadbeni šator” (Bastašić 2018: 57). Sarina majka je „najveća na roditeljskom sastanku, članci natečeni preko tirkiznog kaišića na sandali” (Bastašić 2018: 68), „tiha i široka kao jezero u svijetloplavoj haljini za priredbe” (Bastašić 2018: 27); na proslavi mature gde je Sarina majka u svetloj haljini Lejlina majka je „sama i u crnini, kao znak interpunkcije usred svih tih šarenih bluza" (Bastašić 2018: 30); crno je boja smrti i žalosti, pa na roditeljskom sastanku pored njene niko ne sedi, „kao da je tragedija vaška” (Bastašić 2018: 68). Žena u svetloplavoj haljini posle niza godina postaje ,jednolična hrpa sala” (Bastašić 2018: 127) u invalidskim kolicima; kad se Sara i Lejla tokom putovanja do Beča na kratko zaustave u Banjaluci, Sara majku posmatra iz prikrajka, skrivena iza komšijskog hrasta i ružinog žbuna („Krila sam se iza tuđih ruža i gledala je kako se prežderava.” (Bastašić 2018: 129)), shvativši da Lejlino „kod kuće” ne znači dolazak majci posle dvanaest godina tokom kojih nije došla na očevu sahranu i nije bila $u$ redovnom kontaktu sa njom, te smogne snage samo da pobegne od rodne kuće i skrije se iza spomenika narodnom heroju Ranku Šipki, sanjajući potom san o tome kako spomenik oživljava i vraća joj uspomene (Bastašić 2018: 130 i dalje).

Narativ je pun slika umrlih životinja, kao označitelja nasilne i neumitne, ali krajnje nasumične smrti kojoj su u ratu izloženi i ljudi: pominju se tri Sarine kornjače koje umiru zato što se nije brinula dobro o njima i koje je sahranila ispod bora, polumrtvi vrabac kog Sara zgazi čizmom da mu prekrati muke, potrovani psi u Banjaluci početkom devedesetih, ljubimac beli zec kog drugarice sahranjuju, a svim tim smrtima suprotstavlja se tužan, naoko pedantno režiran, naoko civilizovan i planiran, kraj Majklovog psa Njutna koji je uspavan zato što je oboleo od dijabetesa. Saputnici u mračnom autobusu kojim Sara od Zagreba putuje za 
Mostar, gde će se sastati s Lejlom, nazvani su sovama i guskama, stan gospođe Knežević u Jajcu u kom prenoće prijateljice prepun je pataka keramičkih, plišanih i plastičnih, što će čitaoca podsetiti na ručak u Sarinoj kući kad otac, oblaporno jedući pačetinu, nehajno govori o Arminovom nestanku kao o slučaju koji se zatvara nakon šest meseci (Bastašić 2018: 122). Preteće deluje živi žohar kog devojčica Maša Čeković, drugarica koju Sari majka pokušava da nametne kao alternativu druženju sa Lejlom, čuva u kutiji od šibica; u pitanju je devojčica čiji je sadizam nevešto maskiran prisustvom gomile lutaka u njenoj sobi. Apsurd i patnja koji se vezuju za sudbinu životinja kulminiraju kad po dolasku u Beč junakinje u hotelu simboličnog imena „Veseli lovac” ugledaju niz prepariranih životinja i dobiju ključ s drvenim priveskom na kom je „,medvjeđa glava s urezanim brojem 42 na poleđini”" (Bastašić 2018: 190); igra simbola i značenja se samo nastavlja, bez mogućnosti razrešenja.

\section{ZAKLJUČAK: KAKO U KURIKULUM?}

Uhvati zeca nije delo koje će u književni kanon ući lako i brzo: kao zapažen roman autorke koja pripada mlađoj generaciji pisaca u regionu, i čija poetika svesno i hotimično reflektuje dobro poznate književne i kulturne motive iz dela Luisa Kerola, ovo ostvarenje može da bude primer za ukrštanje različitih tema i uticaja, za preispitivanje motiva doma i porekla, tela i teritorije, ali u velikoj meri može da bude i poprište sukoba sučeljenih filozofskih, istorijskih i ideoloških koncepcija.

Roman Lane Bastašić važan je za analizu u univerzitetskoj nastavi na nekoliko epistemoloških nivoa: kao roman odrastanja, koji inkorporira teme koje su mladim ljudima razumljive i bliske; kao roman o ratu i posledicama rata, što je takođe tematski blisko mladim ljudima; kao roman o identitetu; kao prozni tekst u kom se obilato koriste pesničke metafore, no isto tako i parabole, hiperbole i aluzije; kao prilog izučavanju fantastike u prozi; kao primer aproprijacije tema i motiva u narativu.

I kao jedno od pitanja za kraj ostaje i pitanje naslova ovog rada: da li je Lana Bastašić zaista ispisala novu, postjugoslovensku Alisu, koja egzistira ovde i sada? Ko je u njenom romanu ta zbunjena, ali odlučna i na avanturu saznavanja spremna Alisa? Da li Alisu oličava racionalna i staložena Sara, koja pokušava da artikuliše rasutu sliku sveta, ili je Kerolova junakinja predstavljena u nesputanoj, spontanoj i neprilagođenoj Lejli? Neka od tih pitanja može da reši diskusija o pročitanoj knjizi, upriličena među pripadnicima generacije koja će se sa teškim identitetskim dilemama tek suočavati. 


\section{LITERATURA}

Barnett, R., and Coate, K. (2004). Engaging the Curriculum in Higher Education. London: McGraw-Hill Education.

Bastašić, L. (2018). Uhvati zeca. Beograd: Kontrast izdavaštvo.

Bloom, H. (1994). The Western Canon: The Books and School of the Ages. New York: Harcourt Brace.

Bloom, H. (2002). Genius: A Mosaic of One Hundred Exemplary Creative Minds. New York: Warner Books.

Day, H. (2007). "Helicopters, Jigsaws and Plaits: Revealing the Hidden Language and Literature Curriculum". Pedagogy 7 (3): 534-543.

Eagleton, T. (1983). Literary Theory: An Introduction. Blackwell: Oxford.

Frith, S. (1992). "Literary Studies As Cultural Studies - Whose Literature? Whose Culture?". Critical Quarterly, 34 (1): 3-27.

Gordić Petković, V. (2016). „Krv na ženskim rukama: imaginarna i stvarna krivica u Šekspirovom Magbetu i Čudu u Šarganu Ljubomira Simovića”, u Krv: književnost, kultura, ur. Mirjana Detelić i Lidija Delić (Beograd: Balkanološki institut SANU): 301-312.

Pike, M. A. (2002). "The Canon in the Classroom: Student Experiences of Texts from Other Times". Journal of Curriculum Studies, 35 (3): 355-370.

Richaudeau, F. (1970). "En lisant Roland Barthes: écriture, lecture, relecture et lisibilité". Communication et langages, 8 (6): 15-26.

Svirčev, Ž. (2019). „Putovanje na početak noći”. Polja, 64 (515): 184-186.

Williams, R. (1960). Culture and Society 1780-1950. London: Chatto and Windus.

Vladislava Gordić Petković

University of Novi Sad

Faculty of Philosophy

Department of English Studies

\section{ALICE, HERE AND NOW: CONTEMPORARY LITERATURE IN UNIVERSITY TEACHING}

\section{Summary}

The debate of the literary canon continues, as the ongoing battle to reshape literary heritage has been fought on many fronts. The traditionalists, such as Harold Bloom, assert that aesthetic standards must not be replaced with ethnocentric and gender considerations, whereas the scholars who seek to modernize the canon advocate a more diverse set of literary works in the belief that the dominance of dead, white and male writers perpetuates cultural injustice. The wish to reshape literary heritage is connected to the idea that the 
invisible elements of culture should be made visible and present and that the writers who have been marginalized or neglected should be introduced into the curricula. Contemporary literary texts lack theoretical evaluation which might indicate their relevance, but, on the other hand, encouraging students to search for an interpretational key within their personal and generational experience is worth the effort. The analysis of the novel Catch the Rabbit by Lana Bastašić indicates the immense potential of introducing a work of contemporary literature into the university curriculum.

The author appropriates the narrative of Alice's Adventures in Wonderland in order to relate the conflicting issues of memory and belonging in the post-Yugoslav context. Bastašić reaches for a familiar fictional setting in order to present her characters' internal conflicts as universal, but still reminiscent of the actual Bosnian and ex-Yugoslav issues. Her novel cuts deep into the feeling of otherness imposed by either a traumatic overdose of history or an individual neurosis of non-belonging. Bastašić represents diverging memories and concepts connected with the homeland that was willfully abandoned, but constantly longed for and therefore narrativized. Displacement is painful, but shown to be the only way to rescue oneself, although the protagonists return to the turbulent history of both the family and the homeland with a renewed potential of self-reflection. Lana Bastašić's narrative finds its own way to express the pain, anger, memory and longing through the carefully developed imagery of home, blood, and animals.

Key words: contemporary literature, teaching, gender, canon, curriculum.

Primljeno: 23. 4. 2019.

Prihvaćeno: 13. 6. 2019. 